\title{
A Comparison of Numerical Simulations of Hydrostatic Flow over Mountains with Observations
}

\author{
KLAUS P. HOINKA \\ Institute of Atmospheric Physics, German Aerospace Research Establishment (DFVLR), \\ D-8031 Oberpfaffenhofen, Federal Republic Germany
}

(Manuscript received 2 April 1983, in final form 26 November 1984)

\begin{abstract}
Numerical solutions of a hydrostatic mesoscale model for stratified flow over topography are compared with analytical results and observational data. The numerical model was found to reproduce well phase and amplitude of linear and nonlinear waves provided by analytical models. The model was effective in simulating observed chinook associated with an intense mountain wave. In a nonchinook case the model was successful in reproducing main features of the observed velocity distribution associated with an elevated region of blocking. The observed and simulated momentum flux profiles are almost identical. The comparisons of the model results with observations and analytical results demonstrate the overall ability of the model to realistically simulate mountain wave flow. In a series of numerical experiments we have investigated how far the steepness of the waves depends on stratospheric wind structure and on orography. Our simulations suggest that there is a bifurcation line between the linear and nonlinear regime of flow depending on the magnitude of the stratospheric wind. Tests with an asymmetric orography show significant increase in wave amplitude up to the magnitude which was observed. Finally, two bora-type flows, a cyclonic and one anticyclonic, are simulated and show the expected structure in the wind and temperature fields.
\end{abstract}

\section{Introduction}

In the past few years there has been rapid progress in understanding mesoscale mountain flow through a combination of observational, experimental and numerical modeling studies (see Smith, 1981 for a review). Field experiments, such as the Colorado Lee Wave Program in 1971 or ALPEX in 1982 have provided an important data base, although the data are necessarily limited and not all flow features can be resolved; moreover, field programs are extremely expensive to conduct. In view of this, mesoscale models play an important role in investigating mountain wave flow.

Numerical simulations of airflow over mesoscale topography are presented by Mahrer and Pielke (1977), Klemp and Lilly (1978, hereafter referred to as KL), Peltier and Clark (1979) (PC), among others. Several studies (Pielke, 1974; Pielke and Mahrer, 1975; Mahrer and Pielke, 1978; Pielke and Mahrer, 1978) deal with various features of the model of Mahrer and Pielke (1977), for example numerical schemes or two- versus three-dimensionality. However, a systematic verification of this model for mountain flow problems has yet to be made. The skill of a model can be assessed by comparing its predictions with the results of analytical models and with observational case studies. This will be done in the present study in order to demonstrate the overall ability of the model of Mahrer and Pielke (1977) to realistically simulate mountain wave flow. Henceforth we refer to the applied numerical model as the University of Virginia Mesoscale Model (UVM model).

Most mesoscale models incorporate elaborate parameterizations of physical processes (i.e. boundarylayer formulation, parameterization of humidity processes) and due to the highly complex model structure, it is sometimes difficult to distinguish between the physical and nonphysical aspects of the model results. Therefore it is desirable to investigate first a highly simplified version of the UVM model. We omit frictional effects and even the Coriolis force is neglected; we consider just two-dimensional flows.

In a first numerical experiment we investigate the behavior of the model atmosphere due to small amplitude orographic forcing. The simulated quasilinear hydrostatic waves are compared with analytical solutions presented by Queney (1948). The solution to Long's model (1953), subject to appropriate boundary conditions, provides a useful test for a mesoscale model simulating Boussinesq flows as shown by Lilly and Klemp (1979). In a second test where nonlinear effects play an important role, solutions of Long's model are compared with those obtained from the UVM model. Next we compare the corresponding simulations of the UVM model with the observations of the 11 January 1972 severe windstorm in Boulder, Colorado (Klemp and Lilly, 1975) and with those taken on 17 February 1970 over the Rocky Mountains (Lilly and Kennedy, 1973). 
In terms of physical processes that lead to largeamplitude waves during chinook events, the conclusions of $\mathrm{KL}$ and $\mathrm{PC}$ appear to be very different. In the present paper we investigate to what extent the steepness of the waves depends on stratospheric wind structure and on orography. The purpose is to show that the stratospheric wind profile and its associated shear close to the tropopause could force a severe downslope windstorm. The numerical simulations of Durran and Klemp (1983), KL and PC have shown how the atmosphere responds to simple symmetric topographic forcing. In a second step we perform a simulation using an asymmetric orographic forcing. The purpose is to show numerically that an asymmetric orographic forcing could have attributed to a pronounced forward steepening, an earlier wave breaking at the steepening levels and an increase in the severity of the downslope winds on 11 January 1972.

Due to the successful verification of the UVM model, finally, two bora cases were simulated using this model, one cyclonic (7 March 1982) and one anticyclonic (15 April 1982); both cases were observed during ALPEX.

\section{Description of the numerical model (UVM model)}

\section{a. The equations}

The model used in this study is identical to that developed and applied by Mahrer and Pielke (1977). The two-dimensional equations are transformed from a Cartesian coordinate system to a terrain-following system $\left(x, z^{*}, t\right)$ by the tranformation

$$
z^{*}=\bar{H}(z-h) /(H-h),
$$

where $h$ is the height of the orography, $H$ the height of the free surface and $\bar{H}$ the constant free-surface height $H$ at the time $t=0$. In the $z^{*}$-system the governing equations of motion, heat and continuity are the following neglecting frictional and Coriolis effects:

$$
\begin{array}{r}
\frac{d u}{d t}=-\theta \frac{\partial \pi}{\partial x}+g \frac{z^{*}-H}{\bar{H}} \frac{\partial h}{\partial x}-g \frac{z^{*}}{\bar{H}} \frac{\partial H}{\partial x} \\
+\frac{\partial}{\partial x}\left(K \frac{\partial u}{\partial x}\right)+\frac{\partial}{\partial z}\left(K \frac{\partial u}{\partial z}\right), \\
\frac{d \theta}{d t}=\frac{\partial}{\partial x}\left(K \frac{\partial \theta}{\partial x}\right)+\frac{\partial}{\partial z}\left(K \frac{\partial \theta}{\partial z}\right), \\
\frac{\partial u}{\partial x}+\frac{\partial w^{*}}{\partial z^{*}}-\frac{u}{H-h} \frac{\partial h}{\partial x} \\
+\frac{1}{H-h}\left(\frac{\partial H}{\partial t}+u \frac{\partial H}{\partial x}\right)=0,
\end{array}
$$

$$
\frac{\partial \pi}{\partial z^{*}}=\frac{H-h}{\bar{H}} g / \theta,
$$

where $\pi$ is the Exner function defined by

$$
\begin{gathered}
\pi=c_{p} T / \theta \\
w^{*}=\frac{\bar{H}}{H-h} w-\frac{z^{*}}{H-h}\left(\frac{\partial H}{\partial t}+u \frac{\partial H}{\partial x}\right) \\
+\frac{z^{*}-\bar{H}}{H-h} u \frac{\partial h}{\partial x}, \\
\frac{d}{d t}=\frac{\partial}{\partial t}+u \frac{\partial}{\partial x}+w^{*} \frac{\partial}{\partial z^{*}} .
\end{gathered}
$$

A tendency equation for the height of the free surface is obtained by integrating (2.4) from the ground to the free surface and assuming that $w^{*}=0$ on both boundaries:

$$
\frac{\partial H}{\partial t}=-\frac{1}{\bar{H}} \int_{0}^{\bar{H}} \frac{\partial}{\partial x}(u H-u h) d z^{*} .
$$

The vertical diffusion term is evaluated following Mahrer and Pielke (1978). The advective terrns in (2.2) and (2.3) are evaluated by upstream spline interpolation techniques. The exchange coefficient $K$ is parameterized following Lilly (1969),

$$
K=\alpha(\Delta x)^{3}\left|\frac{\partial \xi}{\partial x}\right|
$$

with $\Delta x$ the horizontal grid spacing. The $x-z$ component of the vorticity $\xi$ is given by

$$
\xi=\frac{\partial w}{\partial x}-\frac{\partial u}{\partial z}
$$

In the present simulation the constant $\alpha$ is set to be equal 0.42. A staggered horizontal and vertical grid is used, as described by Pielke (1974). The model was run with 81 grid points in the horizontal with a uniform spacing of $5 \mathrm{~km}$, and 41 grid points in the vertical. The $z^{*}$ levels from the surface to $1000 \mathrm{~m}$ are 1 and $500 \mathrm{~m}$. Above $1000 \mathrm{~m}$, the levels are spaced $500 \mathrm{~m}$ apart, up to a maximum of $20 \mathrm{~km}$.

\section{b. Initial and boundary conditions}

The surface friction layer of the original version of the UVM model has been eliminated and a free-slip condition is applied at the lower boundary. Special care must be taken in formulating the upper boundary condition since it will fundamentally affect the entire solution. Both theory and observations indicate that hydrostatic waves may extend to high altitudes and produce considerable vertical transport of horizontal momentum. In the present study we impose a viscous layer of $10 \mathrm{~km}$ depth beneath the upper boundary. The energy radiated upward is absorbed in this layer 
by adding damping terms to the right-hand side of Eqs. (2.2) and (2.3):

$$
R_{u}=\tau(z)(u-\bar{u})
$$

and $R_{\theta}$ respectively. The damping coefficient $\tau$ increases gradually with height throughout the absorbing layer with the magnitude chosen so that the dominant wavenumbers are damped most efficiently according to the criteria described by KL. The structure of the absorbing layer is described in detail by Durran and Klemp (1983). Tests with another damping layer proposed by Mahrer and Pielke (1978) have shown similar effective damping as do tests with the applied Rayleigh damping.

The lateral boundary conditions should be designed to prevent wave energy reflection back into the model domain. For the present simulations we have chosen a procedure suggested by Orlanski (1976) and modified by $\mathrm{KL}$. This procedure estimates the phase speed $c$ of a gravity wave impinging on the boundary, and the flow variables are advected out from the boundary with the speed $u+c$. At each vertical level $u+c$ is evaluated according to Orlanski (1976). Then a mean speed of propagation is estimated by averaging $u+c$ along the lateral boundaries (KL). For the present simulations, tests with the simpler Neumann boundary conditions have shown similar results.

Initially the potential temperature and the wind were prescribed for the entire model domain using the inflow profile. The upstream profiles of potential temperature and wind are interpolated from observed soundings to the $z^{*}$-coordinates using cubic splines. For the wind profiles the component of the observed wind that is normal to the barrier is used.

Instead of attempting to specify the detailed mountain terrain we have chosen the simple bell-shaped contour for the airflow over the Rocky Mountains simulation. This "Witch of Agnesi" profile has widely been used because of its easy Fourier decomposition and physically realistic shape. Moreover, KL have used this profile, which is given by

$$
h(x)=\frac{h_{0}}{1+x^{2} / b^{2}},
$$

where $h_{0}$ is the maximum height and $b$ the nominal half-width. The nominal half-width $b$ is set to be twice the grid distance. In the Rocky Mountains case $h_{0}$ is set to be $2 \mathrm{~km}$, which is the approximate difference in height between the Continental Divide and the plains immediately to the east of the Rockies. For the bora simulation we have chosen a realistic mountain profile which is similar to that at the Yugoslavian coastal range. This orography is characterized by a slight increase in height upslope reaching a maximum height of $1000 \mathrm{~m}$ followed by a sharp descent downslope (see Fig. 18).

\section{Comparisons with analytical solutions}

Before describing numerical simulations of airflow over mountains during chinook or bora, we compare numerical simulations with analytic solutions.

\section{a. Linear mountain waves}

The behavior of linear hydrostatic mountain waves is governed by

$$
\frac{\partial^{2} \delta}{\partial z^{2}}+m^{2} \delta=0
$$

The dependent variable $\delta(x, z)$ is the vertical displacement of an air parcel from its undisturbed equilibrium height $\bar{z}$, i.e., $\delta=z-\bar{z}$. The Scorer parameter $m$ is given by

$$
m^{2}=\frac{g^{2}}{c_{p} T \bar{u}^{2}}-\frac{g^{2}}{4 R^{2} T^{2}}
$$

The appropriate lower boundary condition is $\delta(x, h)$ $=h(x)$, where $h$ is the terrain height. The form of $h$ for a bell-shaped mountain is given by Eq. (2.12). The solution to Eq. (3.1) is

$$
\delta(x, z)=\left(\frac{\bar{\rho}}{\rho_{0}}\right)^{-1 / 2} h_{0} b \frac{b \cos m z-x \sin m z}{x^{2}+b^{2}} .
$$

In cases where the mountain height is small (i.e., $10 \mathrm{~m}$ ) the forced wave amplitude becomes linear. Applying $h=10 \mathrm{~m}, N=0.018 \mathrm{~s}^{-1}(T=285 \mathrm{~K})$ and $U=20 \mathrm{~m} \mathrm{~s}^{-1}$ the necessary condition for linearity $N h / U \ll 1$ is fulfilled. In Fig. 1 the solid lines depict the streamlines generated by the nonlinear numerical model for a mountain height of $10 \mathrm{~m}$; they are amplified by 100 for better visualization. The corresponding analytical solution evaluated by Eq. (3.2) is

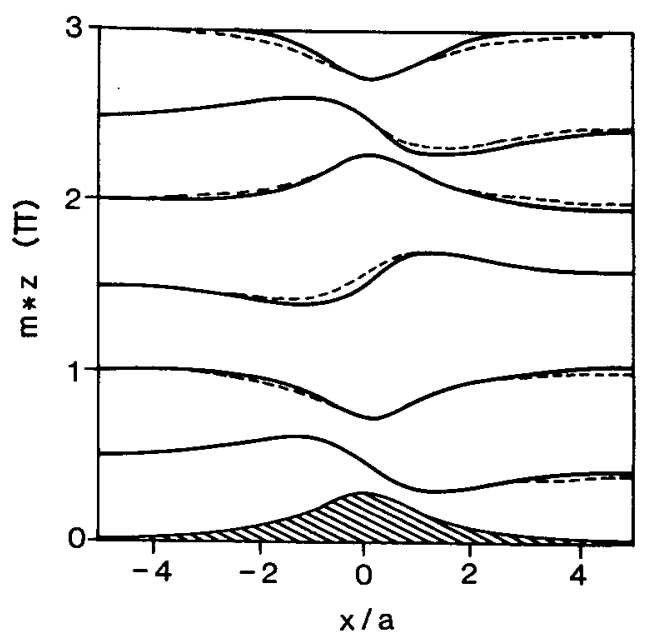

FIG. 1. Comparison of linear analytic (broken) and numerical solution (full) for potential temperature surfaces with $h_{0}=10 \mathrm{~m}$. The amplitudes are amplified by a factor 100 for better visualization. 
shown in Fig. 1 by the broken streamlines. Both solutions are in good agreement considering amplitude and phase.

One of the most important quantitative measures of mountain wave intensity is the exchange of momentum between the atmosphere and the sloping lower boundary. The nonlinear momentum flux $M_{N L}$ is approximated by

$$
M_{N L}(z)=L^{-1} \int_{0}^{L} \bar{\rho} u^{\prime} w^{\prime} d x
$$

where $L$ is equal to $200 \mathrm{~km}$. Within the hydrostatic nonrotating approximation the linear mountain drag $D_{L}$ is given by (Miles and Huppert, 1969)

$$
D_{L}=-\rho_{0} \pi U N h^{2} /(4 L),
$$

with $N$ the Brunt-Väisälä frequency, $\rho_{0}$ a mean density and $U$ the basic flow. Figure 2 shows the vertical distribution of the nonlinear momentum flux normalized by the linear drag value after several timesteps. The model approaches a steady state as soon as the flux becomes about constant with height.

\section{b. Nonlinear mountain waves}

Long's equation (1953) is of second-order quasilinear Helmholtz type. The necessary restrictions for the derivation of this equation are steady-state assumption, no friction, two-dimensionality and hydrostatic, nonrotating flow. Further, the Helmholtz equation becomes completely linear for a Boussinesq fluid if static stability and mean velocity are constant with height. With these assumptions Long's equation be-

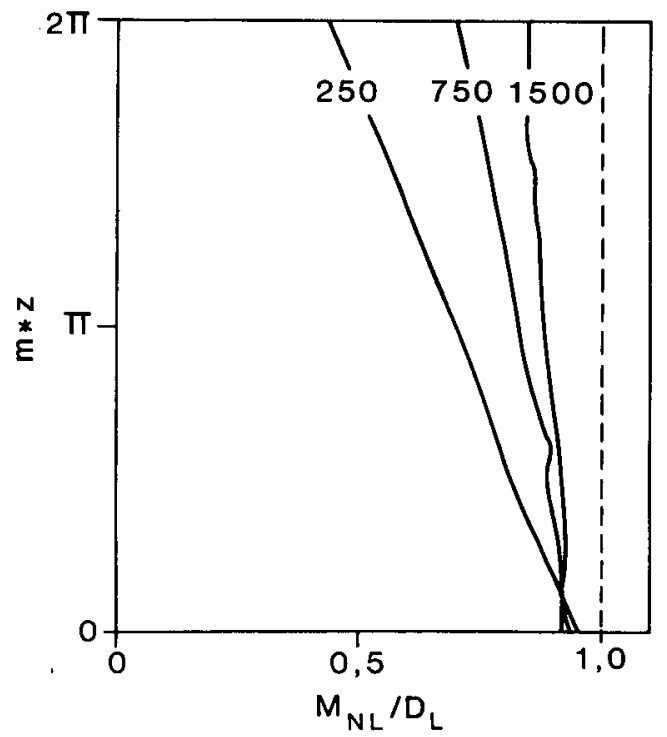

FIG. 2. Vertical flux of horizontal momentum, normalized by its linear hydrostatic value, after several times of simulation; the numbers of time steps are given.

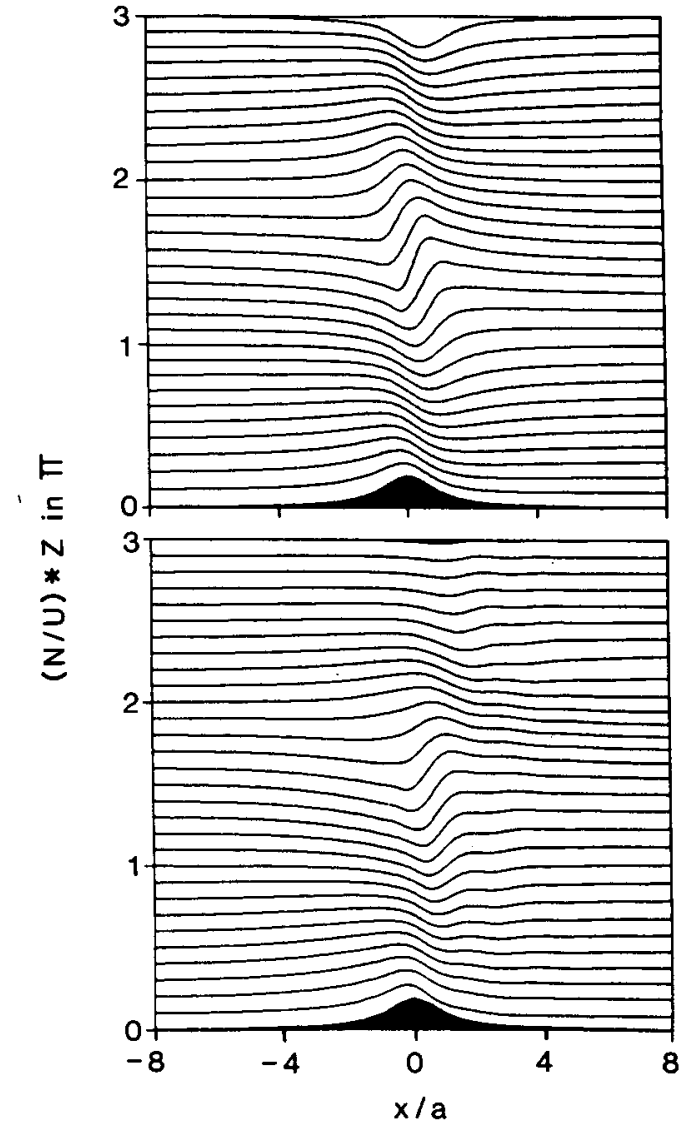

FIG. 3. Numerical (bottom) and analytic (top) Boussinesq solution for $h_{0}=1000 \mathrm{~m}$.

comes (3.1). For this case the parameter $m$ is equal to $N / U$, 'which is the vertical wavenumber. Again, the appropriate lower boundary condition is $\delta(x, h)$ $=h(x)$. Lilly and Klemp (1979) have obtained solutions to the equation subject to a radiative upper boundary condition.

In deriving Long's equation, Long has assumed that the flow is Boussinesq. For this purpose we alter the UVM model to make it Boussinesq. This is accomplished by replacing $\theta$ in Eq. (2.2) by a constant mean background $\theta_{0}$. Moreover, the equation of state (2.5) is modified to

$$
\frac{\partial \pi}{\partial z^{*}}=\frac{g H-h}{\bar{H}} \frac{\theta-\bar{\theta}}{\bar{\theta} \theta_{0}},
$$

with $\bar{\theta}$ the horizontal average of $\theta$. The mountain height is assumed to be $1000 \mathrm{~m}$, and with $U=20 \mathrm{~m}$ $\mathrm{s}^{-1}$ and $N=0.0121 \mathrm{~s}^{-1}$ we arrive at $N h / U=0.6$. This value is large enough to ensure nonlinearity and small enough to be beneath the critical value of 0.85 at which overturning occurs (Miles and Huppert 1969).

The numerical and analytical solutions are plotted in Fig. 3. The phases and amplitudes agree well. in the layer between 0 and $2 \pi$. Above this layer in the 
numerical simulation the waves are obviously damped out. This is due to the vertical wavelength of this flow being $10.5 \mathrm{~km}$. Thus at $N z / U$ equal to $2 \pi$ the damping procedure starts.

\section{Comparisons with observations}

\section{a. The Boulder windstorm on 11 January 1972}

The observed isentropic surfaces and isotachs of horizontal velocity for this event are reproduced in Fig. 4 for convenience (Klemp and Lilly, 1975). To numerically simulate this case we have chosen, following KL, an upwind sounding profile (see Fig. 14 in their paper) based on the National Weather Service 1700 MST sounding taken at Grand Junction, located some $300 \mathrm{~km}$ west of Boulder. For modeling purposes, the ground level on the upwind side of the mountain is taken to be the same as that in the lee $(1700 \mathrm{~m})$. Above the tropopause, the atmosphere is specified to be isothermal with a constant wind of $30 \mathrm{~m} \mathrm{~s}^{-1}$.

The calculated temperature and wind fields after $9 \mathrm{~h}$ of model integration are shown in Fig. 5. The salient features are one enormous wave trough just above the barrier accompanied by a wind maximum at the ground and a minimum aloft. The maximum surface velocity in the lee of the mountain is calculated to be $55 \mathrm{~m} \mathrm{~s}^{-1}$, as obtained by $\mathrm{KL}$. The observed maximum tropospheric displacement in the wave trough is approximately $6.5 \mathrm{~km}$. In our simulation this displacement is only $3.5 \mathrm{~km}$, similar in magnitude to that reported by $K L$. Note that the hydrostatic approximation precludes the simulation of the observed lee waves at lower levels. In summary, the potential temperature and wind fields are well represented in the UVM model predictions (compare with the numerical simulation of KL their Fig. 15).

The observations suggest that the flow in the lower stratosphere is highly turbulent. Another region of strong turbulence is in the midtroposphere, where there is a strong steepening of the wave. These turbulent areas are marked by crosses in Fig. 4 . The Richardson number Ri can be seen as an indication for the occurrence of turbulence, and is defined by

$$
\mathrm{Ri}=g \theta^{-1}(\partial \theta / \partial z)(\partial u / \partial z)^{-2} .
$$

In Fig. 5, areas in which the Richardson numbers fall below 0.25 are marked by crosses. Comparisons with Fig. 4 show that these regions can be identified with the observed regions of strong turbulence.

The circulation shown in Fig. 5 is not in a steady state. We may quantify the degree of nonsteadiness by evaluating the mountain drag as a function of time. The mountain drag is the force exerted by the earth through differential pressures on the windward and leeward slopes. For two-dimensional topography this force is defined as

$$
D_{N L}=-\frac{1}{L} \int_{0}^{L} p_{S} d h / d x d x,
$$

where the surface pressure $p_{S}$ equals $p_{S}[x, h(x)]$.

In Fig. 6 (top) the temporal evolution of the nonlinear drag is shown by the full line, and the broken line represents the linear drag (Eq. 3.4). We see that the surface drag increases continuously as a function of time, showing evidently that the numerical simulation is not steady. Peltier and Clark (1979) point out that, in their calculations, the surface drag in the nonlinear regime greatly exceeds the linear prediction by roughly $300 \%$. In our simulation, the excess is more than this value. Figure 6 corroborates that the flow is highly unsteady.

\section{b. The airflow over the Colorado Rockies on 17 February 1970}

The observed temperature and wind field for this event are reproduced in Fig. 7. This situation is quite different from that shown in Fig. 4. Strong surface winds are not present and the wave appears to reach appreciable amplitude only near the tropopause. The calculations are performed in an atmosphere $15 \mathrm{~km}$ deep topped by a $5 \mathrm{~km}$ absorbing layer in which the wind speed and temperature are taken to be constant. In contrast, $\mathrm{KL}$ use an atmosphere $20 \mathrm{~km}$ deep topped by a $10 \mathrm{~km}$ absorbing layer. Following $\mathrm{KL}$ we have chosen an upwind sounding profile (see Fig. 17 in their paper) based on the National Weather Service 0500 MST sounding taken at Grand Junction. Above the tropopause, the atmosphere is specified to be isothermal with a constant wind of $10 \mathrm{~m} \mathrm{~s}^{-1}$.

Figure 8 shows the simulated flow fields after $10 \mathrm{~h}$ model time, at which stage a quasi-steady state is attained. The wave just below the tropopause is reversed in phase from that at low levels in agreement with observations, but the model amplitude is not as strong as the observed. This might be due to the absorbing layer being too shallow and being located too close to the region where steepness of the wave increases. In this respect, the KL simulation gives a slightly better representation of the upper-level flow and, in particular, of the wave. Note that the position of the wave and the associated low wind-speed layer in the model is in approximately the same height range as that observed. In contrast, the KL simulation locates this wave about one $\mathrm{km}$ too high. In the observations we have a level at which $u$ vanishes; with our model the minimum wind speed results in magnitude lower than $5 \mathrm{~m} \mathrm{~s}^{-1}$, similar to the simulation of KL. The calculated low-level wind speed in the lee is less than $30 \mathrm{~m} \mathrm{~s}^{-1}$, as observed. In summary, our simulation and that of $\mathrm{KL}$ agree remarkably well and both compare well with the observed structure.

Most of the observed turbulence occurs at heights between 12 and $15 \mathrm{~km}$ (Fig. 7). Another region with light turbulence is observed close to the mountain on 


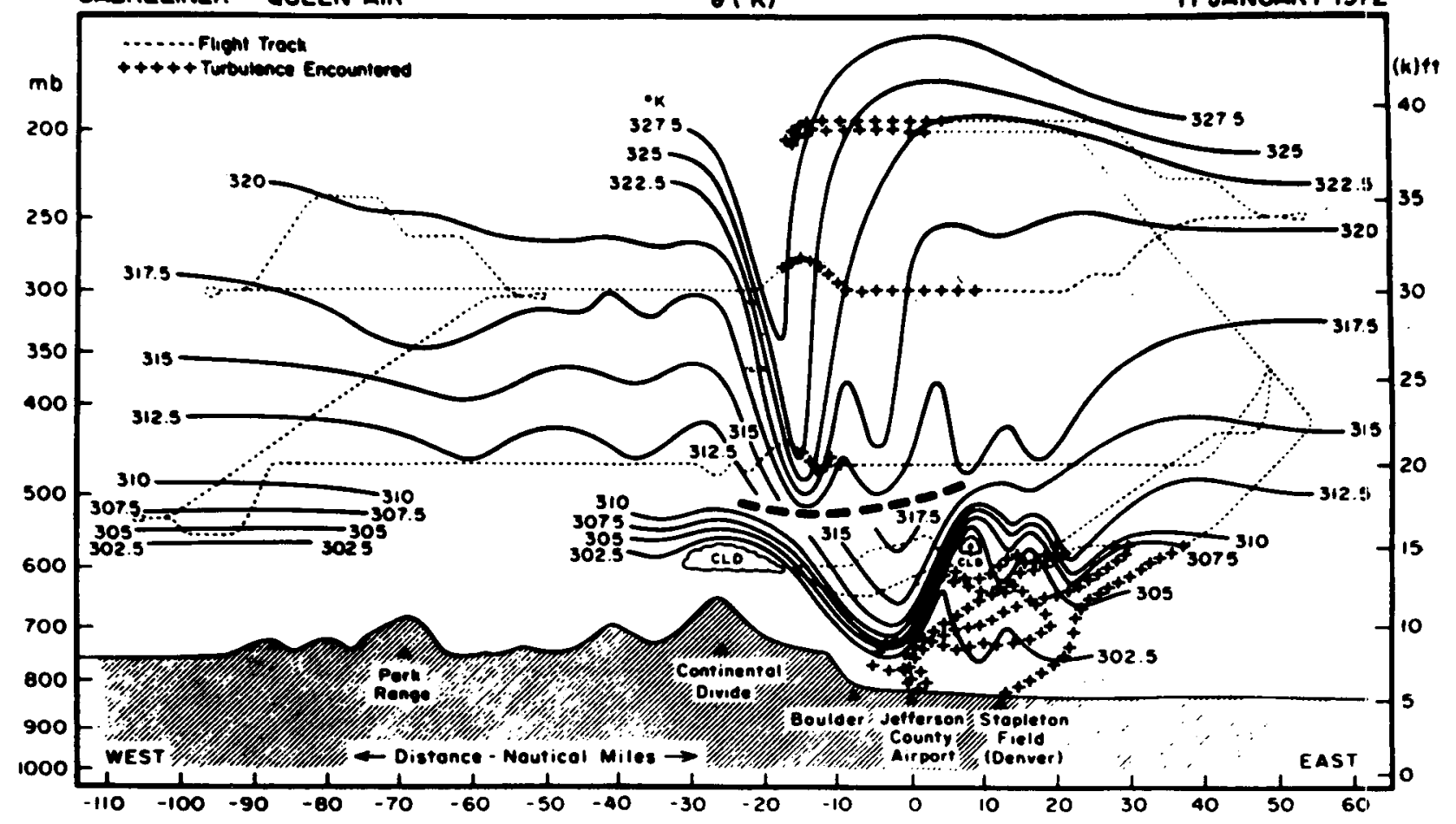

SABRELMER

$U$ (mprace)

11 JAMUARY 1972

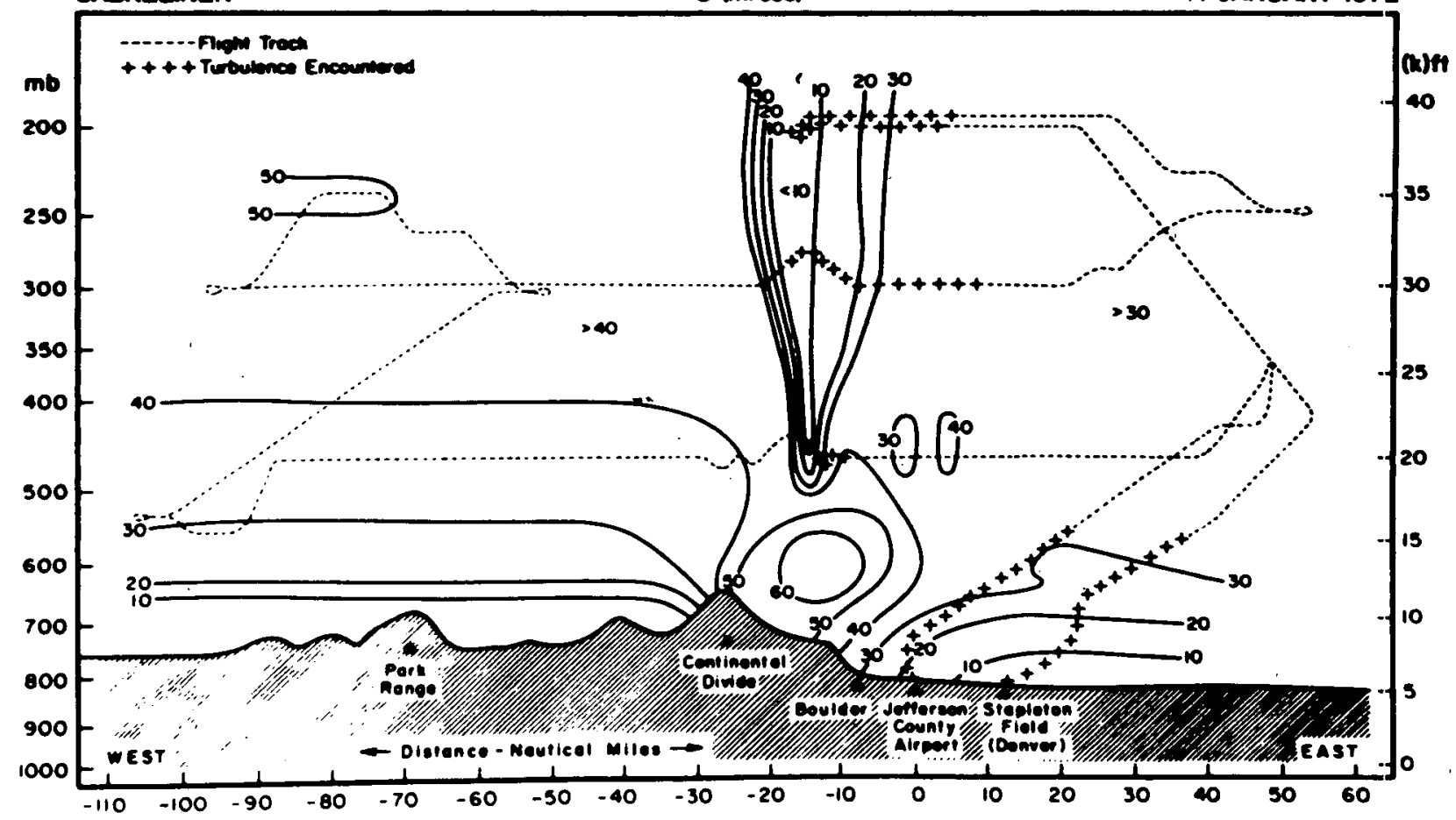

FIG. 4: Cross section of the potential temperature (top) and contours of horizontal velocity (bottom) along an east-west line through Boulder, as obtained from rawinsonde observations and airborne measurement (taken from Klemp and Lilly, 1975).

the leeward side. The numerical model predicts a Richardson number smaller than 0.25 in the layer between 12 and $15 \mathrm{~km}$ (see Fig. 8), and also on the windward side in the lower troposphere. Observations of turbulent intensity in the latter region are unavailable. 

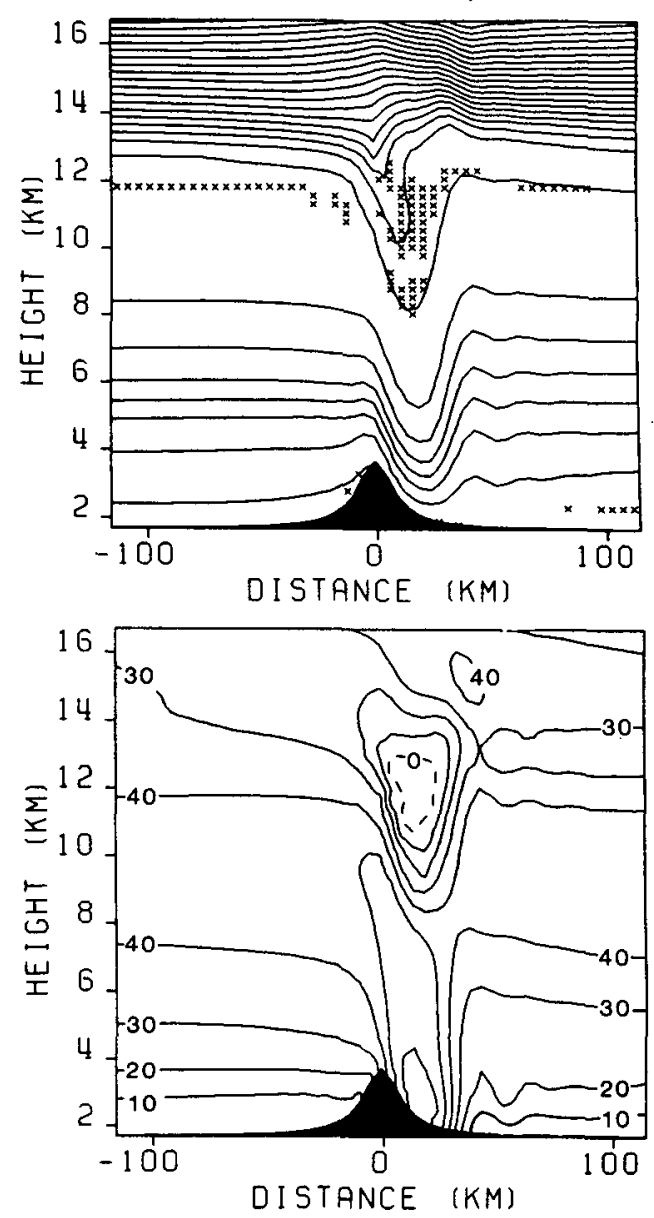

FIG. 5. Numerical simulation of the 11 January 1972 case (Rocky Mountains). Potential temperature surfaces (top); contours of horizontal wind components in $\mathrm{m} \mathrm{s}^{-1}$ (bottom). Crosses mark regions with Richardson numbers smaller than 0.25 .

We may quantify the degree of steadiness by evaluating the surface wave drag as a function of time, plotted in Fig. 6 (bottom). The quasi-steady state behavior is evident for times greater than one hour. Finally, we remark on the magnitude of the total momentum flux. To compare our flux values with those reported by $\mathrm{KL}$ and with the observations we must evaluate them over a horizontal distance of $200 \mathrm{~km}$ centered on the mountain. This distance is the length of flight traversed during the event. Comparable flux values from the model were obtained by calculating the total momentum flux across the entire domain and then dividing the results by the averaging distance of $200 \mathrm{~km}$ (Eq. 3.3).

The momentum flux is about constant up to a height of $12 \mathrm{~km}$ and decreases above (Fig. 9, full line). Remark that this decrease starts beneath the damping layer. This is due to the fact that a strong damping occurs in the region where $\mathrm{Ri}$ drops below 0.25 . This damping can be seen clearly if we compute the horizontal mean value of the exchange coefficient [Eq. (2.9)]. In the case of large coefficients we expect strong damping. In the vertical profile of the horizontal mean of $K$ we note a strong increase in magnitude between 12 and $15 \mathrm{~km}$ (Fig. 9, dotted line) and, further, a decrease in the damping layer. This decrease is due to the two-dimensional vorticity Eq. (2.10) approaching zero where the disturbances are smoothed out, which is the case in the damping layer. The strong magnitude of $K$ just beneath the damping layer leads to the strong decrease of the momentum flux in the layer $12-15 \mathrm{~km}$. The magnitude of the momentum flux in the troposphere is approximately $0.7 \mathrm{~Pa}$. This result is similar to that obtained by $\mathrm{KL}$; they reported a vertically constant profile between 4 and $16 \mathrm{~km}$ of $0.6 \mathrm{~Pa}$, simulated with their model. The magnitude of the observed momentum flux was between 0.3 and $0.9 \mathrm{~Pa}$ (Lilly and Kennedy, 1973).

Klemp and Lilly (1975) have shown that special profiles of wind and stability are sensitive to topographic forcing. They pointed out that if the height of the tropopause above the mountain corresponds to a vertical half-wavelength, intense wave response should be expected associated with strong downslope winds. In the Boulder storm case the atmosphere was "tuned" for intense wave response (vertical wavelength $\sim 18 \mathrm{~km}$ ). The height of the tropopause during the
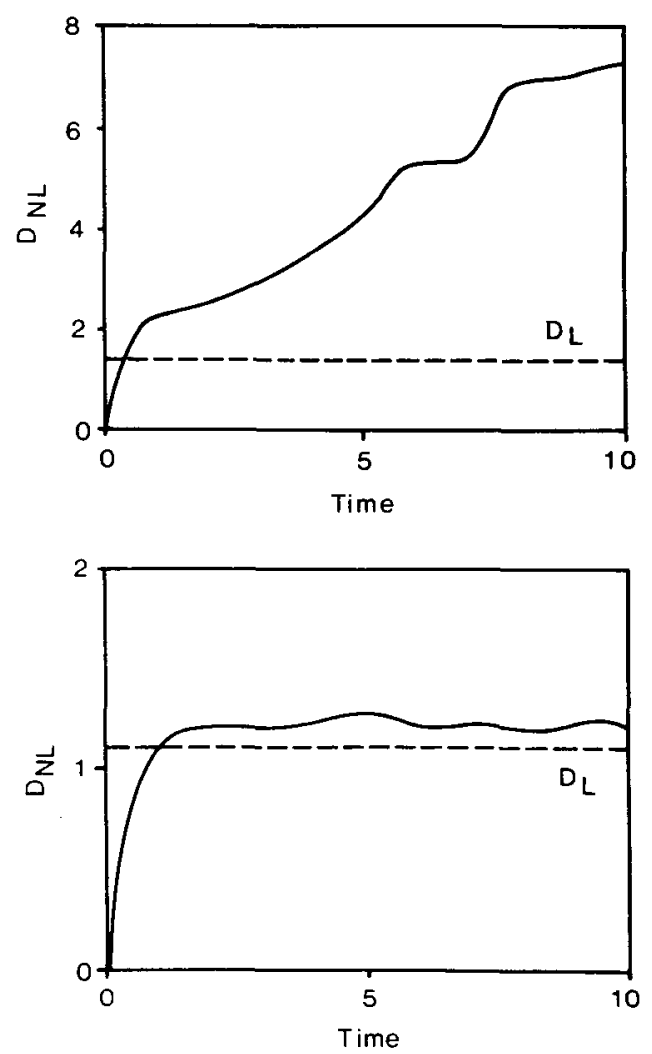

Fig. 6. The mountain drag as a function of time for the 11 January 1972 case (top) and the 17 February 1970 case (bottom). Broken lines mark corresponding linear predictions. Mountain drag is given in $\mathrm{Pa}$ and time in $\mathrm{h}$. 


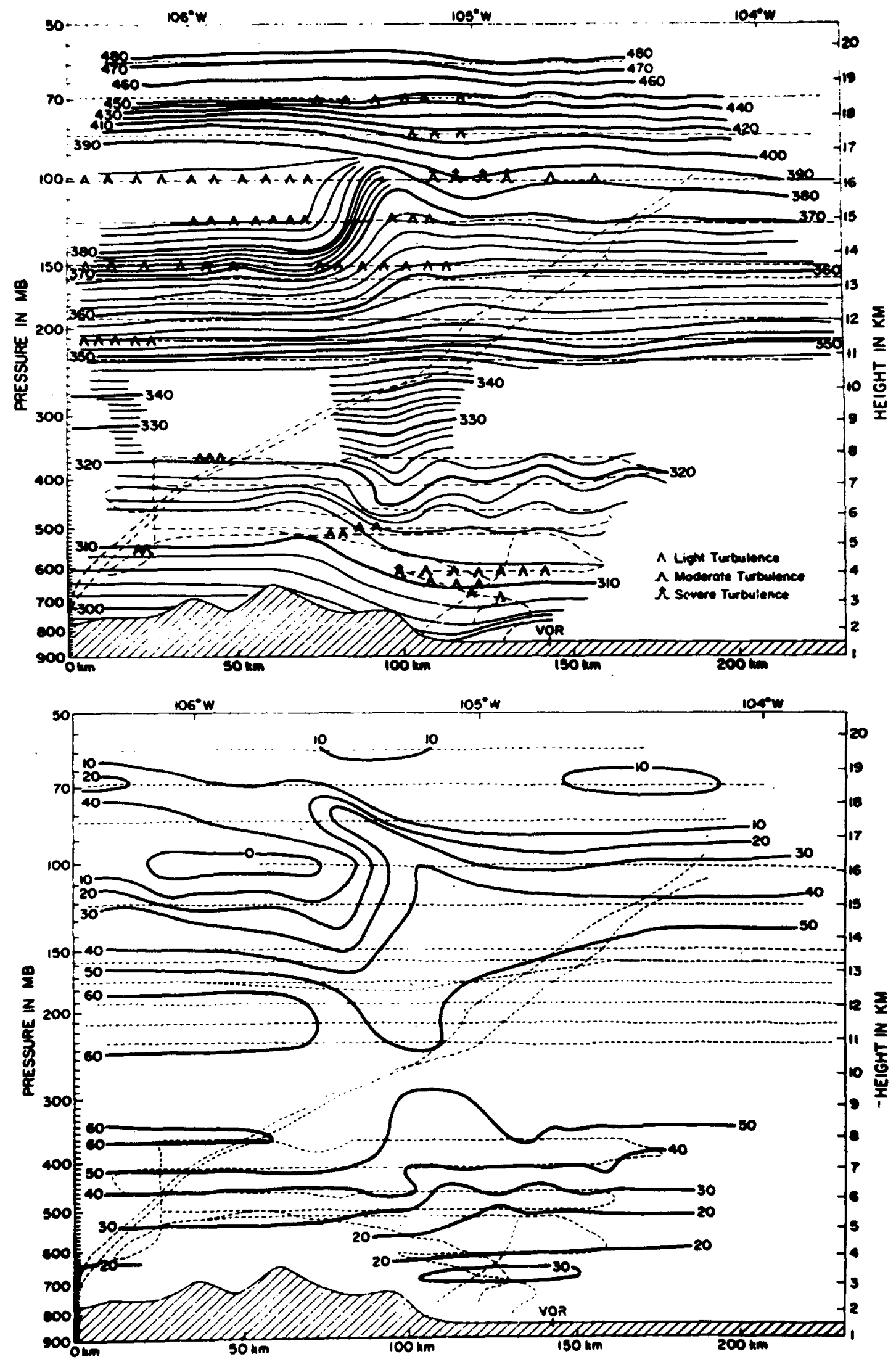

FIG. 7. Potential temperature cross section (top) and westerly wind components (bottom) for the 17 February 1970 case (taken from Lilly and Kennedy, 1973). 

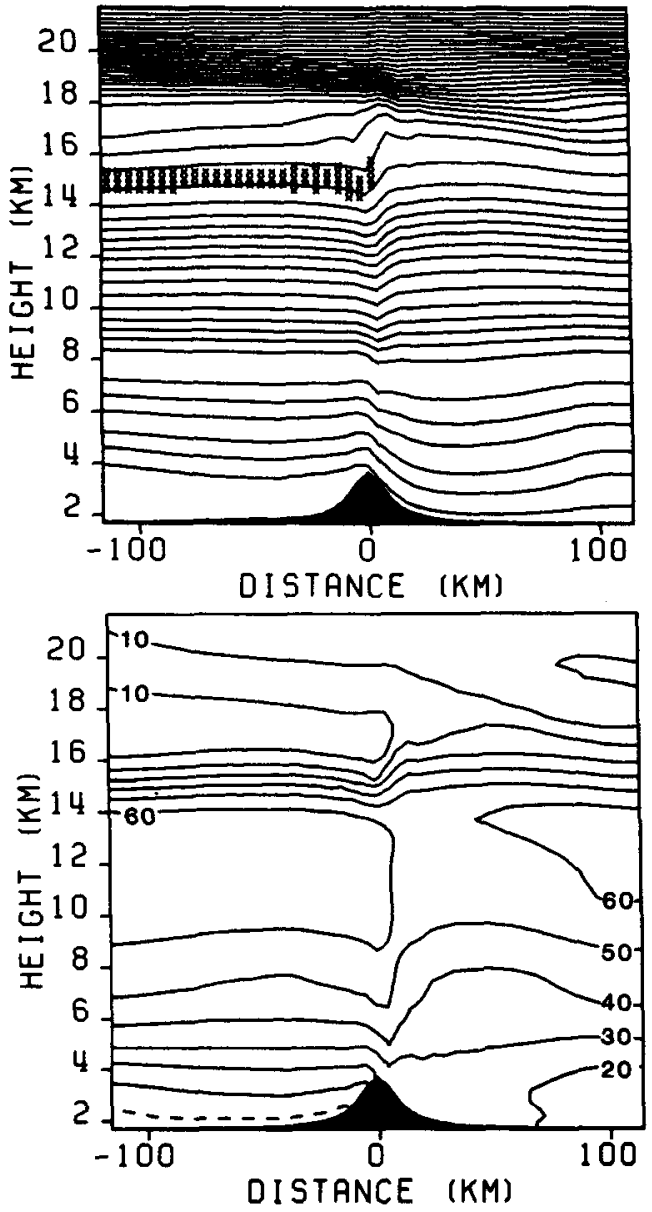

FIG. 8. As in Fig. 5 but for the 17 February 1970 case.

Colorado case was located $5 \mathrm{~km}$ higher than during the chinook event. With a vertical wavelength of about $25 \mathrm{~km}$ the atmosphere was clearly not tuned and neither intense wave response nor downslope windstorm occurred.

\section{Increasing steepness of the mountain wave}

In the last section we showed a successful simulation of the observed intense wave and windstorm on 11 January 1972. However, the magnitude of the observed wave amplitude $(6.5 \mathrm{~km})$ was larger than the magnitude of the simulated hydrostatic wave (4.5 $\mathrm{km})$. In this section we consider a possible steepening of the wave and the increase of its associated windstorm due to the magnitude of the stratospheric wind $u_{s t}$ and due to asymmetric orographic forcing.

\section{a. The wind shear at the tropopause}

Peltier and Clark have shown that different stratospheric wind profiles linked with different shear close to the tropopause cause different regimes of flow in the model atmosphere, provided that the profile of the Scorer parameter remains unchanged. Their model has produced linear responses with stratospheric winds of $30 \mathrm{~m} \mathrm{~s}^{-1}$ while with $u_{s t}=20 \mathrm{~m} \mathrm{~s}^{-1}$ the model has shown strong nonlinear amplification of the waves. Here we present a series of numerical simulations covering a broader variety of stratospheric wind profiles to investigate whether there is similar sudden change from linear to nonlinear regions of flow in a hydrostatic atmosphere. All simulations are performed using the stability profile measured at Grand Junction on 11 January 1972 . The observed wind profile was used up to $10 \mathrm{~km}$ and $\boldsymbol{u}_{s t}$ was specified by replacing the observed wind by $0,10,20,30,40$ and $50 \mathrm{~m} \mathrm{~s}^{-1}$ above $12 \mathrm{~km}$. In the layer between 10 and $12 \mathrm{~km} \mathrm{a}$ spline adaption between the lower and upper profiles was applied.

The numerical results after $5 \mathrm{~h}$ simulation time are shown in Fig. 10. Strong nonlinearity is synonymous with the occurrence of highly steepened streamlines. This is obviously the case in Fig. $10 \mathrm{~d}\left(u_{s t}=30\right.$

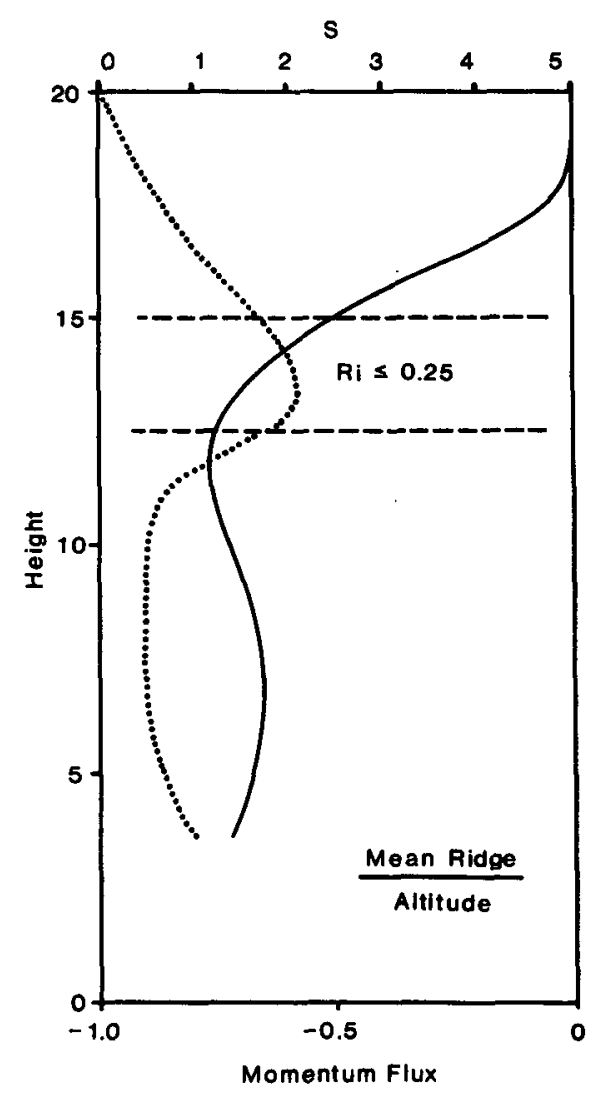

FIG. 9. Momentum flux profile (full line) for the 17 February 1970 case. In the layer between 12.5 and $15 \mathrm{~km}$ the Richardson number drops below 0.25 . Dotted line is vertical profile of $S$, which is the horizontal average of the exchange coefficient [see Eq. (2.9)] normalized by its vertical average. The momentum flux is given in $\mathrm{Pa}$ and the height in $\mathrm{km}$. 

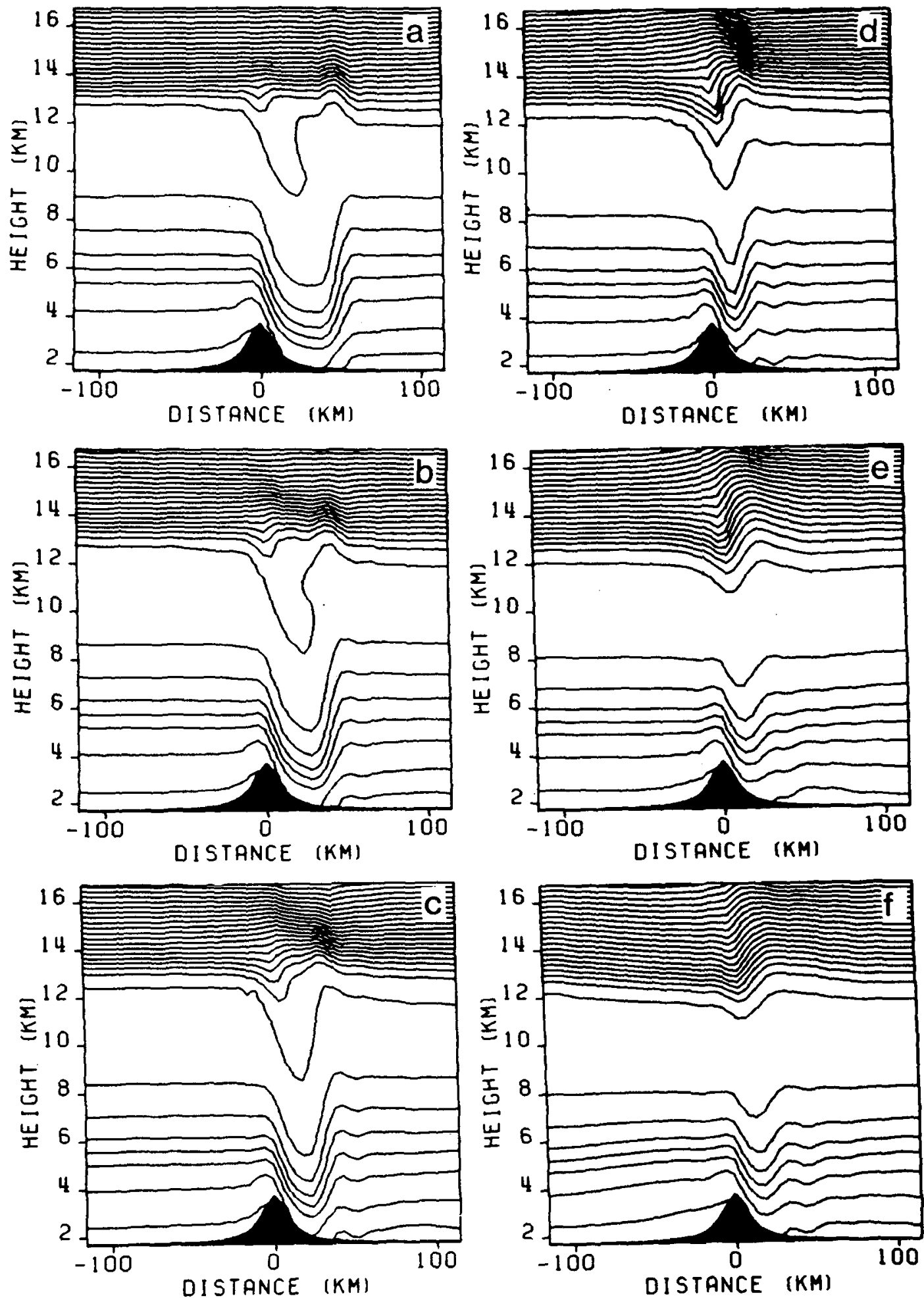

FIG. 10. Numerical simulation of the Boulder storm case on 11 January 1972 with various wind profiles in the stratosphere: $0,10,20,30,40,50 \mathrm{~m} \mathrm{~s}^{-1}$ respectively $\mathrm{a}, \mathrm{b}, \mathrm{c}, \mathrm{d}, \mathrm{e}, \mathrm{f}$.

$\mathrm{m} \mathrm{s}^{-1}$ ). For winds lower in magnitude (Figs. 10a-c; $u_{s t}=0,10,20 \mathrm{~m} \mathrm{~s}^{-1}$ ) strong steepening followed by wave breaking occurred previous to the time as shown. The circulation in this nonlinear regime is characterized by a strongly steepened wave associated with a strong downslope windstorm of about $60 \mathrm{~m}$ 
$\mathrm{s}^{-1}$. For $u_{s t}$ greater than $30 \mathrm{~m} \mathrm{~s}^{-1}$ (Figs. 10e-f; $u_{s t}$ $=40,50 \mathrm{~m} \mathrm{~s}^{-1}$ ) steepening can be seen, but overturning has not occurred. The circulation in this quasi-linear regime is characterized by weak amplification and weaker winds on the leeside of the obstacle, which is 50 (Fig. 10d), 40 (Fig. 10e) and 30 (Fig. 10f) $\mathrm{m} \mathrm{s}^{-1}$. Figure 10 suggests that there is a sudden change from linear to nonlinear wave amplification dynamics for stratospheric winds $u_{s t}$ between 20 and $30 \mathrm{~m} \mathrm{~s}^{-1}$.

To emphasize the previous result the temporal evolution of the wave drag at mountain top level are plotted in Fig. 11. As expected, the drag increases with increasing amplitude of the hydrostatic wave, which was forced by the increase in wind shear at the tropopause in response to the decrease in stratospheric wind. But the important feature is that after $10 \mathrm{~h}$ simulation time the magnitudes of the simulated wave drag for $u_{s t}$ equal to 40 and $50 \mathrm{~m} \mathrm{~s}^{-1}$ are close together; the same is valid for $u_{s t}$ smaller than $30 \mathrm{~m}$ $\mathrm{s}^{-1}$. However, the magnitude of the last drags is three times the magnitude of that obtained for strong stratospheric winds. This difference suggests that there is a bifurcation line between the linear regime characterized by low wave drag and the nonlinear regime characterized by high wave drag.

The continuous profile of the ratios of surface wave drag to linear drag is shown in Fig. 12. The lower (upper) broken line indicates the ratios performed by the UVM model after $2 \mathrm{~h}(5 \mathrm{~h})$ simulation time. The increase with time in the nonlinear regime obviously emphasizes the bifurcation line between the linear and nonlinear regime of flow between $u_{s t}$ equal to 20 and $30 \mathrm{~m} \mathrm{~s}^{-1}$. Additionally the ratios obtained after $2 \mathrm{~h}$ simulation time by PC (crosses), Durran and Klemp (1983) (circles) and by Clark and

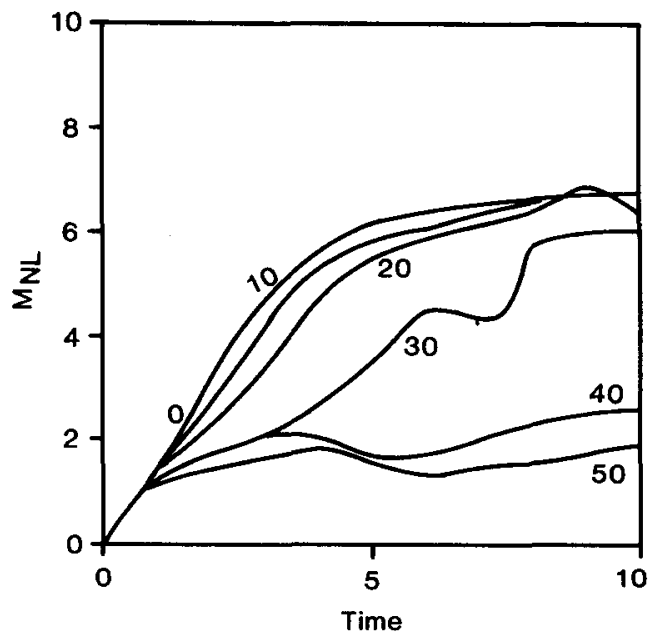

Fig. 11. The temporal evolution of the wave drag (Pa) at mountain top level on 11 January 1972 applying various stratospheric wind $u_{s t}: 0,10,20,30,40$ and $50 \mathrm{~m} \mathrm{~s}^{-1}$.

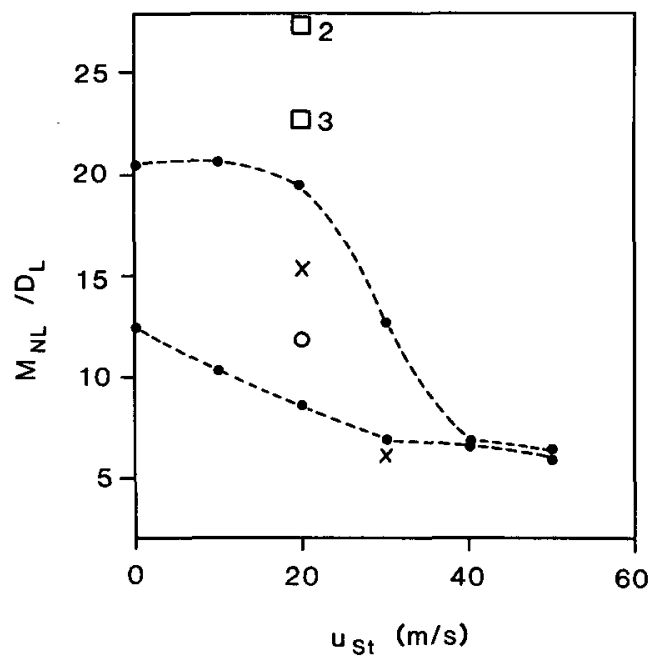

FIG. 12. Ratios of the nonlinear surface wave drag to the linear wave drag as a function of the stratospheric wind $u_{s t}$. The upper (lower) broken line marks the ratios obtained by the UVM model after 5 (2) $\mathrm{h}$ simulation time. Also the ratios reported by PC (crosses), Durran and Klemp (1983) (circles) and Clark and Farley (1984) (squares), all after $2 \mathrm{~h}$ simulation time. The numbers 2 and 3 indicate two- and three-dimensional simulations.

Farley (1984) (squares) are shown. The results for $u_{s t}$ $=20 \mathrm{~m} \mathrm{~s}^{-1}$ of PC as well as those of Durran and Klemp were taken from an unsteady simulation; this means that the ratios are increasing further. The ratios obtained by Clark and Farley (1984) are ratios after reaching an approximate steady state where the number 2 (3) marks a two- (three-) dimensional simulation. The differences between the results of PC and those of Clark and Farley may be due in part to differences in initialization.

Our results confirm the bifurcation line between the linear and nonlinear regime of flow as reported by PC. This confirms in part the strong nonlinear amplification of the wave, which appears to be produced by supercritical steepening and subsequent breaking of the mountain wave in the lower stratosphere, as suggested by PC. Our results show also that in the linear flow regime the severity of the windstorm increases with increasing amplitude of the hydrostatic mountain wave (Fig. 10d-f). However, in the nonlinear flow regime (Fig. 10a-c) we observe a further increase in wave amplitude but the magnitude of the low-level wind speed remains nearly $60 \mathrm{~m} \mathrm{~s}^{-1}$. This suggests that the mechanism proposed by PC might force the strong amplitude of the mountain wave, but that there is no need of this mechanism for the occurrence of strong surface winds.

\section{b. The mountain profile}

The numerical simulations of Durran and Klemp (1983), KL, PC and those presented here have shown the way in which the atmosphere responds to simple symmetric topographic forcing. In this section we 
perform a simulation using an asymmetric orographic forcing. The purpose is to show numerically that an asymmetric orographic forcing could contribute to a pronounced forward steepening, an earlier wave breaking at the steepening levels and an increase in the severity of the downslope winds. The studies of Lilly and Klemp (1979) and Smith (1977) indicate how and why the response tends to be a strong function of the terrain shape.

A more realistic contour of the Colorado Front Range might be an asymmetric profile with a gradual upslope from Park Range to the Continental Divide and a steep downslope down to Boulder (see Fig. 4). This type of profile is obtained by applying the mountain profile [Eq. (2.12)] with a downslope nominal half-width of $b=10 \mathrm{~km}$ and an upslope halfwidth of $b=40 \mathrm{~km}$.

The isentropic fields predicted by the UVM model are displayed in Fig. 13. It must be compared with Fig. 5, in which the prediction is given for a symmetric orographic forcing. The amplitude of the wave is 6.5 $\mathrm{km}$, similar to the observed data. After $4 \mathrm{~h}$ wave breaking has occurred; this is significantly earlier than in the case with symmetric forcing. The simulated low-level wind maximum is $75 \mathrm{~m} \mathrm{~s}^{-1}$, which is larger than the observed maximum wind. Additionally, the location of the wind maximum is shifted slightly downstream. Both features might be due to the fact that no boundary-layer effects reduce the velocities.

In Fig. 14 we show the evolution in time of the wave drag at mountaintop level for simulations with various upslope nominal half-widths between 10 (bellshaped) and $60 \mathrm{~km}$. As expected, the magnitude of the wave drag forced by the leeside-steepened mountain $(b=20,40,60 \mathrm{~km})$ is larger than for the bellshaped mountain. Additionally, the drags simulated by the asymmetric mountain are of similar magnitude and all are about $30 \%$ larger than the drag obtained with symmetric forcing.

The previous simulation of the 11 January 1972 windstorm showed strong steepening forced by a slightly asymmetric orography. The question remains whether this is also the case for the nonchinook event on 17 February 1970. Figure 15 shows the isentropic and wind fields of a simulation with an asymmetric orography with an upslope (downslope) nominal width of $40 \mathrm{~km}(10 \mathrm{~km})$. There is almost no change in flow patterns compared to the case with symmetric forcing (Fig. 8). The momentum flux profile is similar to that obtained for symmetric forcing (Fig. 9).

This is a remarkable result. For two different flows, a chinook and a nonchinook event, the model atmosphere responded differently to asymmetric orographic forcing. For the nonchinook event the simulated flow field is similar to that obtained with symmetric forcing. For the chinook event a more pronounced steepening, an earlier wave breaking at steepening levels and an increase in the severity of the windstorm was obtained by applying asymmetric orographic forcing.

\section{The numerical simulation of two bora events}

The bora is a cold downslope windstorm best known from observations along the northeasiern Adriatic coast. During ALPEX several missions were flown successfully to obtain data during bora events. Since the data analysis of the bora missions is not terminated at the moment (Smith, 1982) we cannot compare our results to the ALPEX data. However, it has been demonstrated in the foregoing sections that the UVM model is capable of successfully simulating airflow over mountains. Therefore, we will perform numerical simulations of two bora events.

The observations suggest that during the Yugoslavian bora a strong inversion is present at approximately the $2 \mathrm{~km}$ height (Yoshino, 1976). Beneath this level the wind blows normal to the barrier (from the northeast), whereas above it the wind is parallel to the barrier (southeast) or comes from the southwest. A distinction is made between the anticyclonic and the cyclonic bora, depending on whether a cyclone exists close to the surface at Italy or not. At $500 \mathrm{mb}$ we find in the cyclonic case a developed cyclone over Italy, very frequently a cutoff low which leads to winds from the southeast along the Yugoslavian coast. In the anticyclonic case at $500 \mathrm{mb}$ we find a trough, located at $10^{\circ} \mathrm{E}$, leading to winds from the southwest along our region of interest.

The synoptic situation for both bora events is plotted in Fig. 16. The cyclonic case is a typical one, since the upper tropospheric structure of the anticyclonic event is characterized by a cutoff low easit of Spain. Nevertheless, the mesoscale dynamical features at the Dalmatian coast are typically of anticyclonic type, similar to those observed with an upper-air trough at $10^{\circ} \mathrm{E}$.

For both bora events the soundings (1200 GMT) of Zagreb, located $130 \mathrm{~km}$ upstream, are used; they provide a good data base of the upstream wind and temperature structure during the bora (Fig. 17). In both profiles an inversion above Zagreb is noticeable at about $2000 \mathrm{~m}$. It is well known that this inversion close to mountaintop height upstream of the barrier is favorable for the occurrence of strong downslope winds. The thickness of both inversion layers is quite different: $1000 \mathrm{~m}$ (15 April) and $200 \mathrm{~m}$ (7 March). However, the most important difference between the events is their stability characteristic beneath the inversion layer. Neutral stratification was observed on 15 April, whereas during the cyclonic event on 7 March a stable stratified flow with $N=0.015 \mathrm{l} \mathrm{s}^{-1}$ occurred. Note that the upstream temperatures beneath the stable layer during the cyclonic case are much lower than during the anticyclonic event.

The wind speed in the surface layer is about $10 \mathrm{~m}$ 

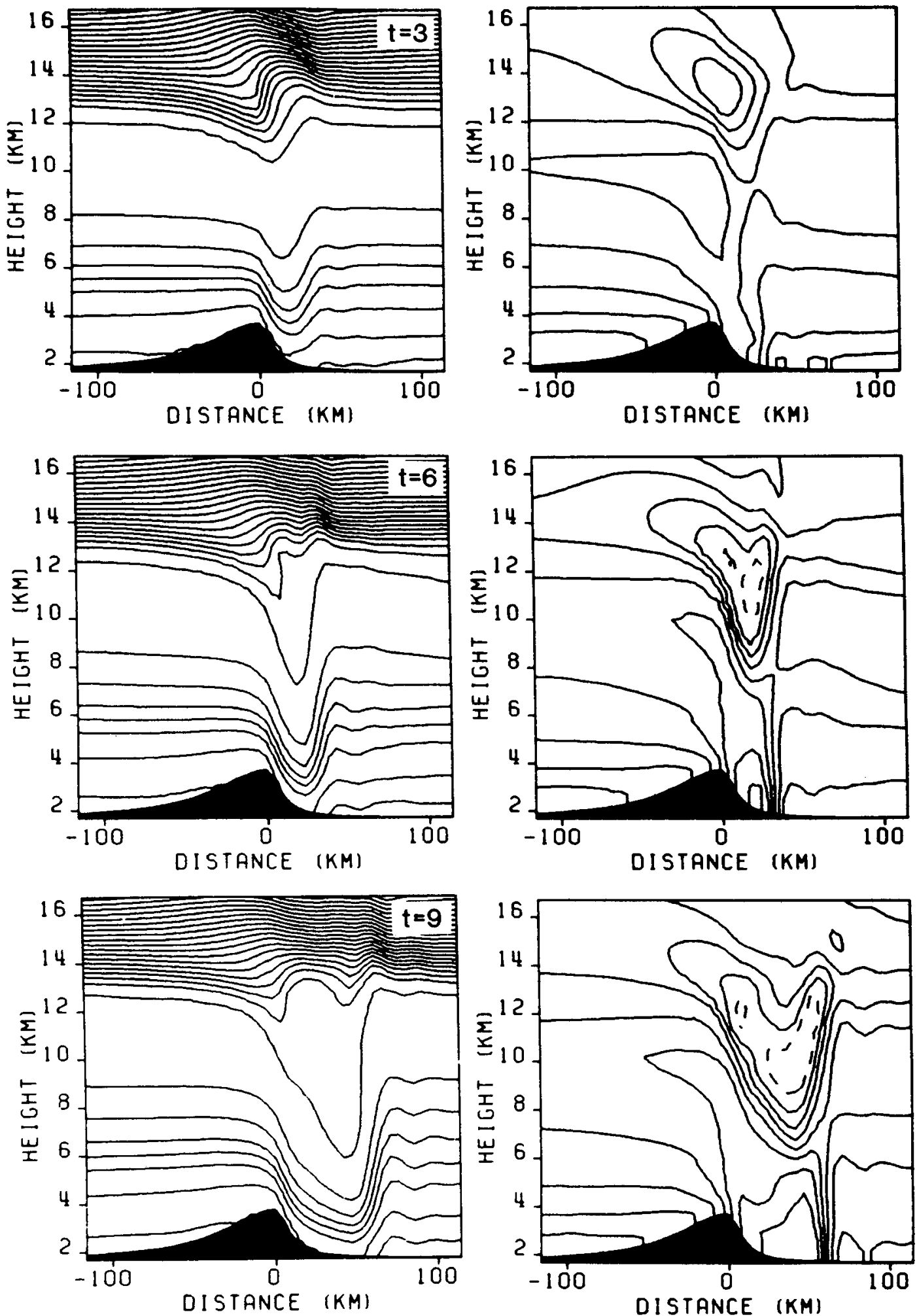

FIG. 13. Numerical simulation of 11 January 1972 case (Rocky Mountains) with a sharply downsloping mountain. Evolution in time of the isentropic surfaces (left) and wind speed (right). Times shown are $3,6,9 \mathrm{~h}$. The contour interval is $10 \mathrm{~m} \mathrm{~s}^{-1}$. 


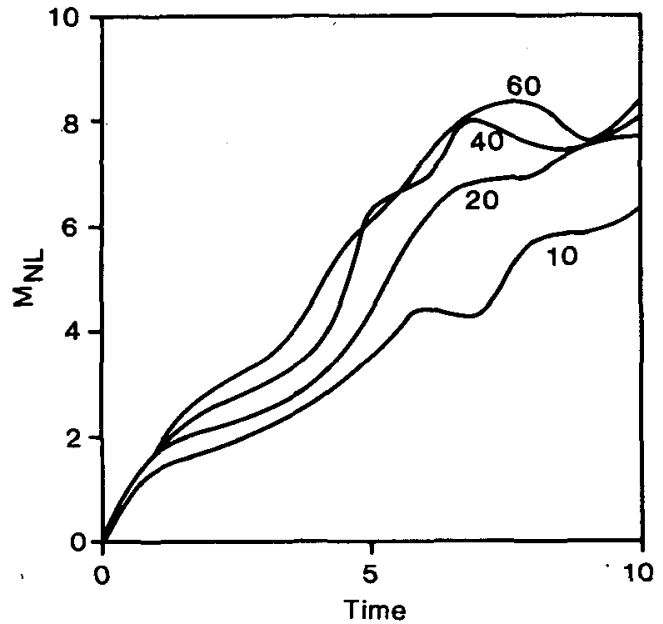

FIG. 14. The evolution of the wave drag $(\mathrm{Pa})$ at mountaintop level for various mountain types: with a downslope $b=10 \mathrm{~km}$ and an upslope $b=10,20,40,60 \mathrm{~km}$ [see Eq. (2.12)]. The time is given in $h$.

$\mathrm{s}^{-1}$ during the cyclonic bora, which is twice the magnitude of the wind during the anticyclonic event. This is due to the surface wind speed being generally higher under the combined influence of a well-developed high and low (cyclonic bora).

The presence of the strong inversion seems to give the flow a hydraulic nature. For this type of flow the characteristic Froude number is defined by

$$
F=U[g \Delta \theta \cdot Z / \bar{\theta}]^{-1 / 2},
$$

where $U$ is the mean wind speed in the bora air, $Z$ the height of the inversion surface and $g$ the gravity constant. Here $\bar{\theta}$ is the mean potential temperature at the inversion and $\Delta \theta$ the temperature difference between both layers near the inversion. It has been shown (Long, 1954) that hydraulic jumps must be expected for Froude numbers greater than unity above mountain crests.

Because the bora is a relatively shallow flow it is reasonable to use a vertical grid with a grid distance of $200 \mathrm{~m}$, and to have a model top at $8 \mathrm{~km}$. For the anticyclonic case with winds aloft from the southwest we have performed several numerical experiments to test the influence of the flow aloft on the low-level dynamics beneath the inversion. The results were identical to vanishing flow aloft.

\section{a. The anticyclonic bora on 15 April 1982}

In Fig. 18 the numerical simulation of this event is given. Beyond the mountain crest the air descends rapidly towards the sea to ascend again well off the coast. This hydraulic jump nature of the bora is corroborated by observations (Yoshino, 1976). In the present case a wind speed of $13 \mathrm{~m} \mathrm{~s}^{-1}$ is simulated above the mountain crest, whereas $15 \mathrm{~m} \mathrm{~s}^{-1}$ was observed. The magnitude of the wind increases up to $16 \mathrm{~m} \mathrm{~s}^{-1}$ in the low levels in the lee downstream close to the barrier.

The Froude numbers are given in Table 1 for the atmosphere above Zagreb, above the mountain crest and above Pula, located $80 \mathrm{~km}$ downstream. The observed and simulated numbers over the mountain crest are close to unity.

\section{b. The cyclonic bora on 7 March 1982}

The numerical simulation of this case is shown in Fig. 19. We see an even stronger descent of the vwave in the lee than in the preceding event. The velocity just above the mountain crest is $21 \mathrm{~m} \mathrm{~s}^{-1}$, increasing up to $28 \mathrm{~m} \mathrm{~s}^{-1}$ in the lower lee close to the sea. Moreover, this strong wind belt extends further downstream than it was simulated to do for the anticyclonic bora.
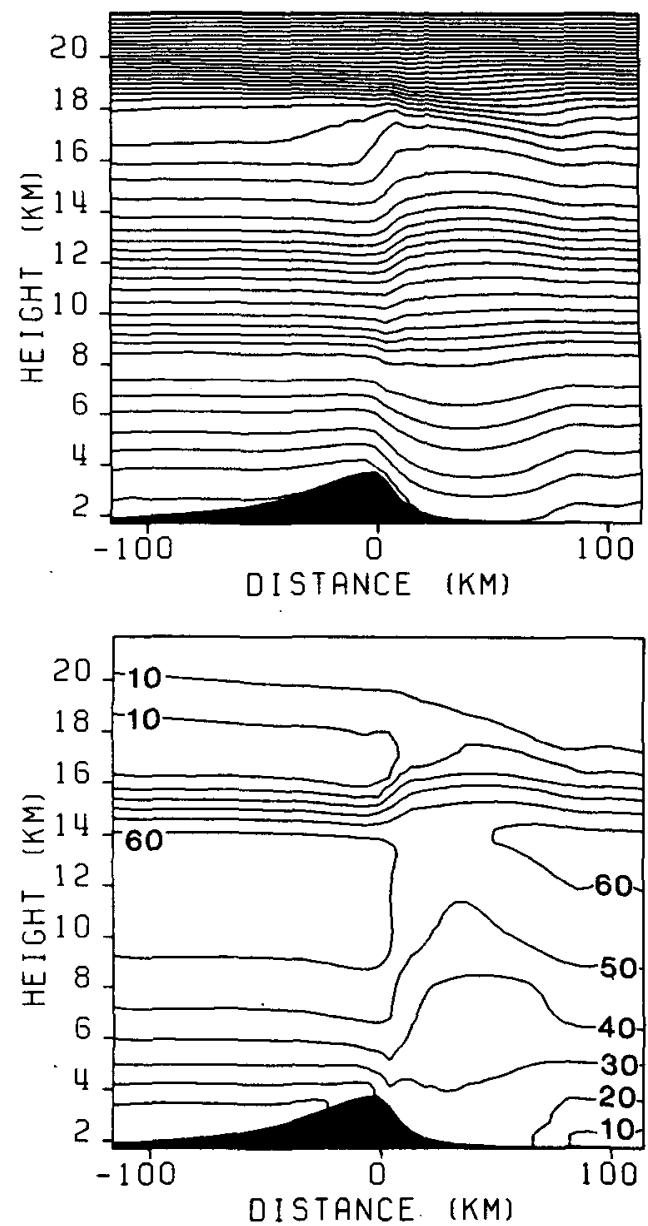

FIG. 15. Numerical simulation of 17 February 1970 case (Focky Mountains) applying a sharply downsloping mountain with $b=10$ km (downslope), $b=40 \mathrm{~km}$ (upslope) [see Eq. (2.12)]. Potential temperature surfaces (top); contours of horizontal wind components in $\mathrm{m} \mathrm{s}^{-1}$ (bottom). 


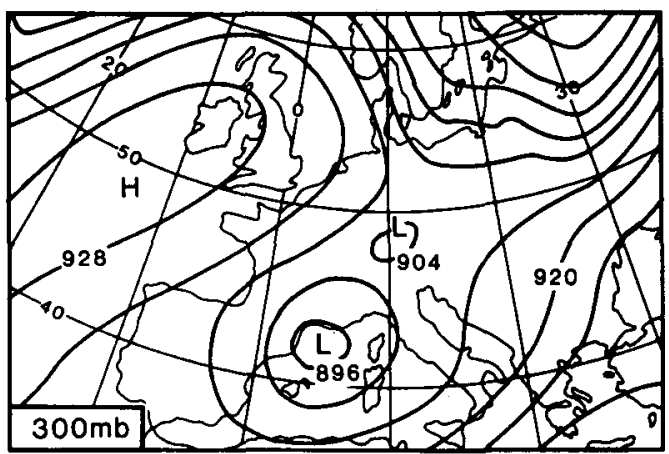

Anticyclonal Bora

$15 / 4 / 82$

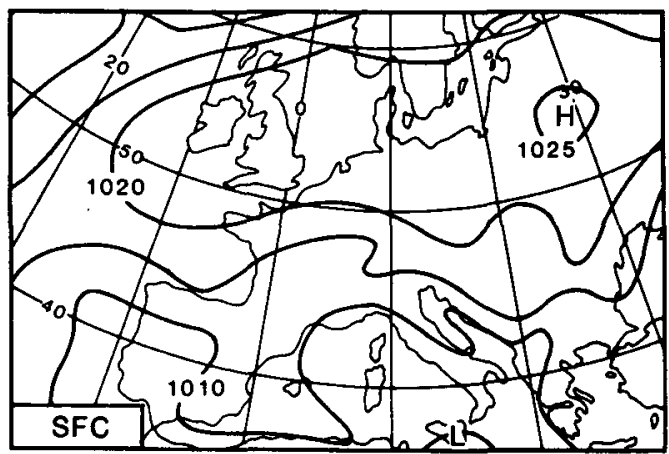

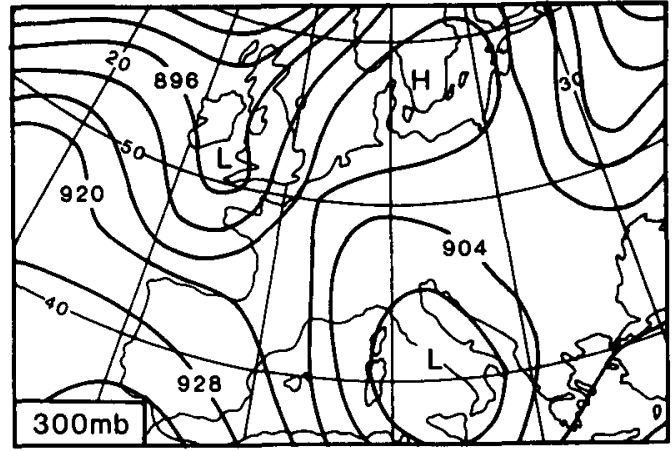

Cyclonal Bora

$7 / 3 / 82$

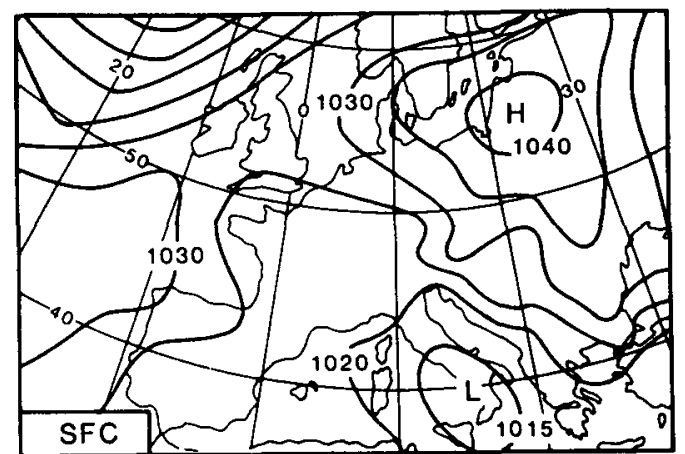

FIG. 16. Surface weather chart (bottom) and $300 \mathrm{mb}$ chart (top) for the 15 April 82 and the 7 March 82 bora cases.

The Froude numbers (Table 1) of this simulation are strong in magnitude above the crest, indicating a hydraulic jump type of flow. In the rawinsonde observations above Zagreb a very shallow inversion layer was found $(100-200 \mathrm{~m})$, whereas above Pula no inversion layer was recognized. The observation suggests that this strong hydraulic jump type of flow has destroyed the shallow inversion layer in the lee above Pula, perhaps through vertical turbulent mixing. However, in the simulation the inversion layer is present (Fig. 19) because a vertical turbulent mixing procedure is not applied in the model.

Why, then, are the Froude numbers larger during the cyclonic case than those obtained during the anticyclonic event? The main reason is the different upstream stability characteristic of the layer beneath the inversion. In the presence of a stable layer the dynamics force the strong descent of potentially warmer air beyond the mountain crest. Very cold air is transported to the barrier and flows rapidly beneath the cool air located downstream. This leads to strong winds above the crest and the flow is characterized by $F$ substantially larger than unity. In the case of neutrally stratified flow beneath the inversion, the magnitude of $F$ must be smaller than for the stable stratified case because the winds above the crest are smaller due to lower temperature difference between the windward and leeward sides. In case of $F$ close to unity, even in neutrally stratified flows a hydraulic jump type of flow could occur; this is obviously the case during the anticyclonic bora. All of this suggests that the surface lee wind speed is generally higher in the cyclonic case than in the anticyclonic case, which is confirmed by the numerical simulations.

A further corroboration is shown in Fig. 20, where the mountain drag is given in its temporal evolution. It can be seen clearly that the magnitude of the mountain drag for the cyclonic bora (7 March 1982) is three times as much as that of the anticyclonic bora.

\section{Summary}

In this paper we have described numerical simulations of flows over finite-amplitude topography using the model of Mahrer and Pielke (1977). The numerical model was found to reproduce well phase and amplitude of linear and nonlinear hydrostatic mountain waves provided by analytical models. The simulation of a chinook case was successful in obtaining strong wave of approximately $3.5 \mathrm{~km}$ in amplitude accompanied by a wind maximum at the ground and a minimum aloft. The numerical simulation of a nonchinook event shows good resemblance to observed data. We obtained the observed elevated region of blocking near the tropopause with a strong absorption of wave energy in this region. The simulated momentum flux is about $0.6 \mathrm{~Pa}$ and constant with height. 

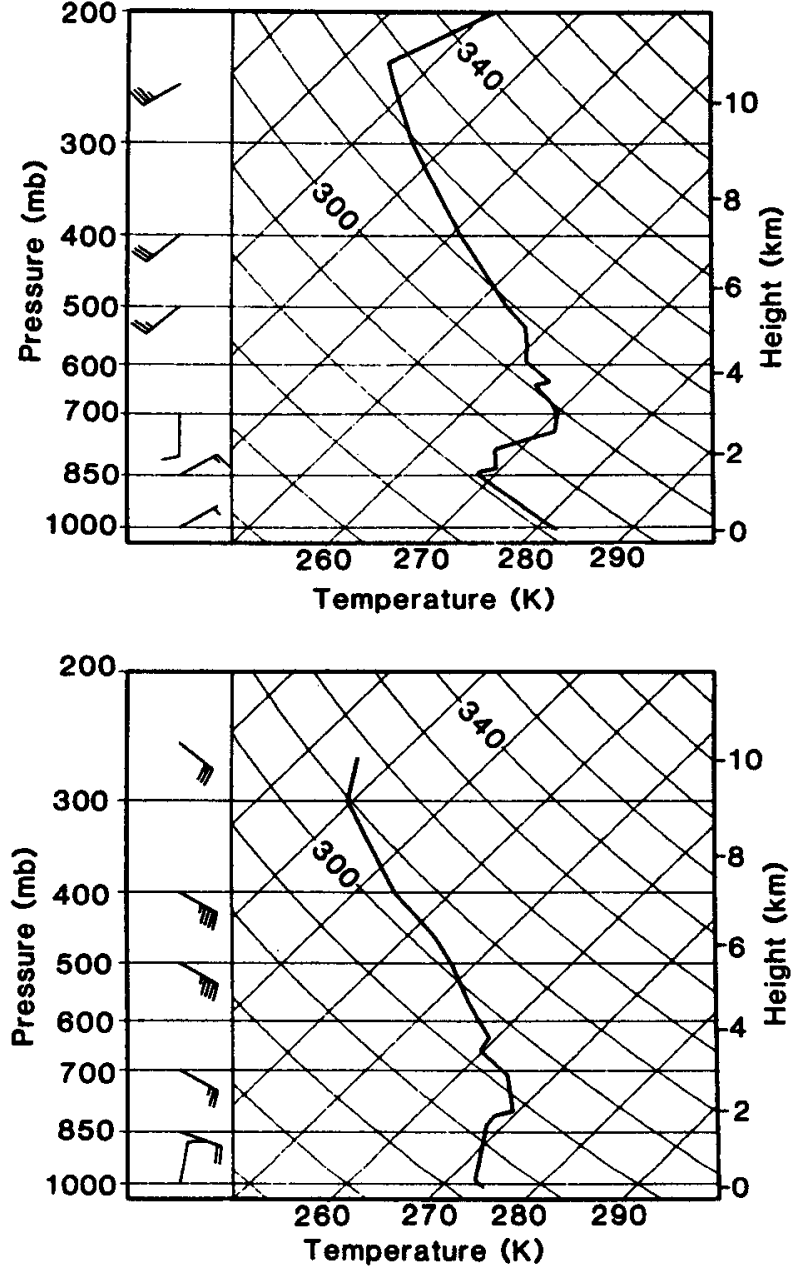

FiG. 17. Zagreb sounding at 1200 GMT 15 April 1982 during an anticyclonic bora (top) and at 1200 GMT 7 March 1982 during a cyclonic bora (bottom). Wind barbs at the left represent the wind speed (kt) and wind direction using standard meteorological notation.

This profile is identical to that simulated by $\mathrm{KL}$ and is in good agreement with the observations. The present study has demonstrated the ability of the Mahrer-Pielke model to deliver solutions that match analytical results as well as meteorological observations of hydrostatic airflow over mountains.

In a series of numerical experiments we have investigated to what extent the steepness of the waves depends on stratospheric wind structure and on orography. Our simulations show that there is a bifurcation line between the linear and nonlinear regimes of flow. This line is near $20-30 \mathrm{~m} \mathrm{~s}^{-1}$ of stratospheric winds for the Boulder windstorm. Low stratospheric wind speeds associated with strong shear in the vicinity of the tropopause lead to strong nonlinear amplification of the mountain wave and large wind speeds linked with slight shear force linear wave amplification. Tests with an asymmetric orography show significant increase in wave response up to the magnitude observed for the chinook case. For
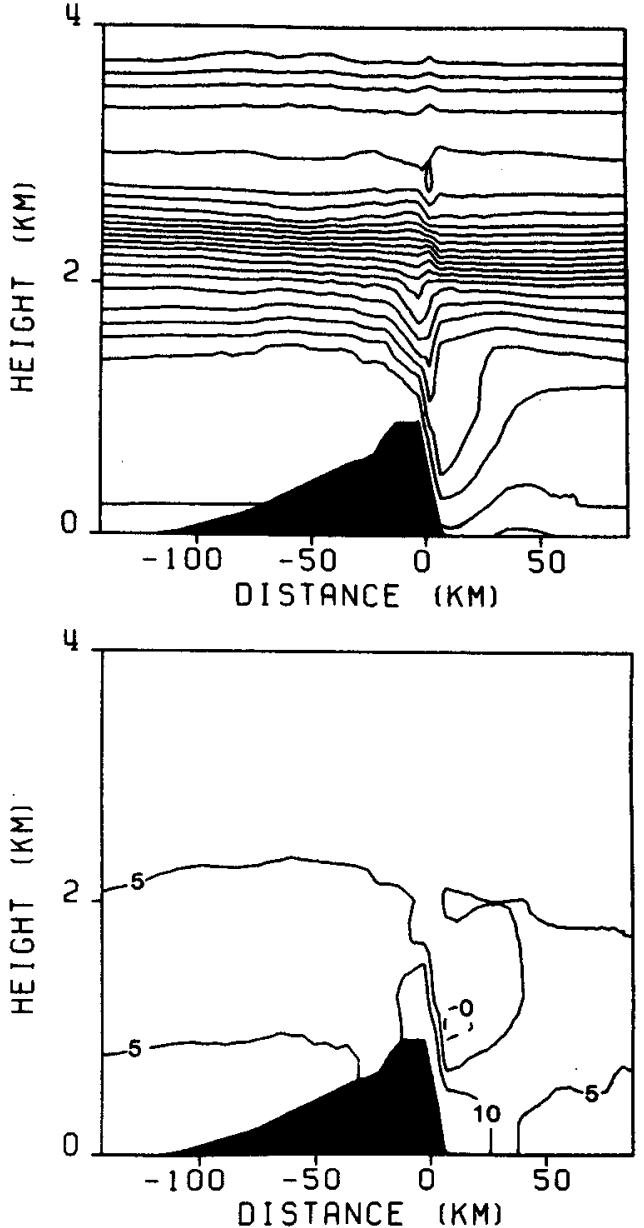

FIG. 18. Numerical simulation of the bora on 15 April 1982. Potential temperature surfaces (top); contours of horizontal viind components in $\mathrm{m} \mathrm{s}^{-1}$ (bottom).

a nonchinook event the simulated flow field was similar to that obtained with symmetric forcing. Our results suggest that mountain asymmetry and partial reflection from the tropopause could have contributed to the strong amplification of the mountain wave and its associated windstorm on 11 January 1972.

The simulation of the bora shows the two-layer structure with an inversion at a height of $2 \mathrm{~km}$. Approaching the barrier this inversion drops sharply to the Dalmatian Sea. This behavior gives the flow a natural hydraulic jump which is confirmed in the magnitude of the observed and calculated Froude

TABLE 1. Observed and simulated Froude number for two bora cases for the atmosphere above Zagreb $(130 \mathrm{~km}$ upstream), the mountain crest and Pula (80 km downstream).

\begin{tabular}{lccccc}
\hline & \multicolumn{2}{c}{$\begin{array}{c}\text { Anticyclonic bora } \\
\text { 15 April 1982 }\end{array}$} & & \multicolumn{2}{c}{$\begin{array}{c}\text { Cyclonic bora } \\
\text { 7 March 1982 }\end{array}$} \\
\cline { 2 - 3 } \cline { 5 - 6 } & Observed & Simulated & & Observed & Simulated \\
\hline Zagreb & 0.25 & 0.25 & & 0.67 & 0.67 \\
Mountain crest & 0.90 & 1.10 & & - & 1.96 \\
Pula & 0.49 & 0.24 & & - & 0.47 \\
\hline
\end{tabular}



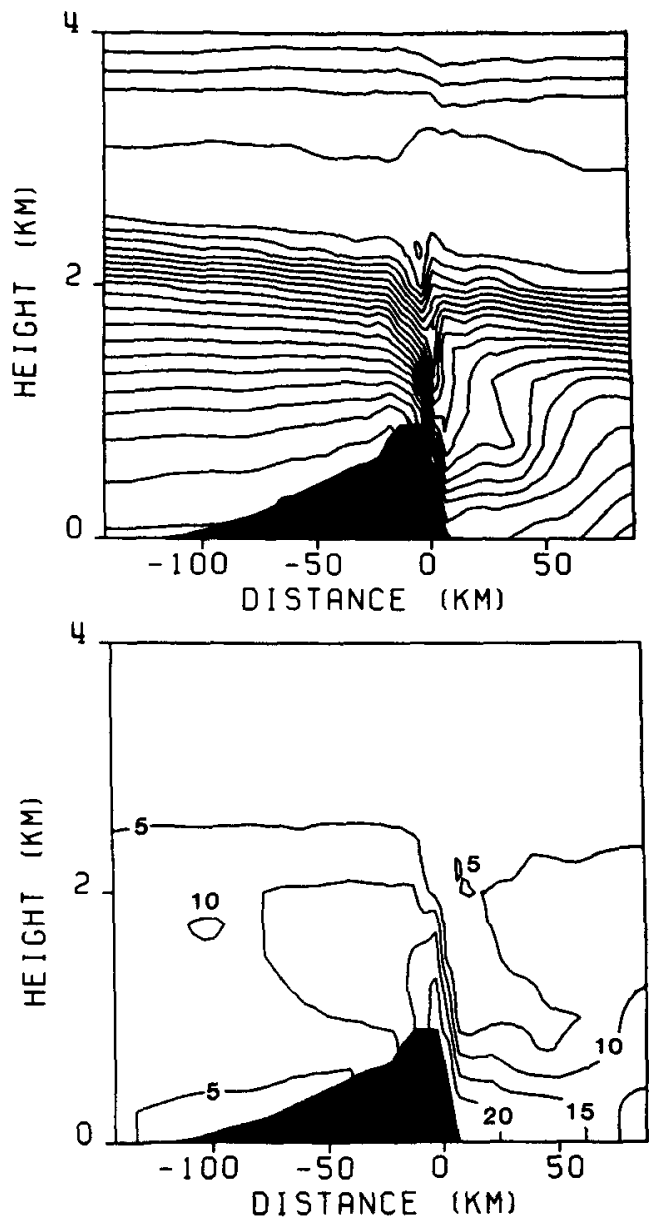

FIG. 19. As in Fig. 18 but for 7 March 1982.

numbers close to unity just above the barrier. The magnitude of the wind speed close to the mountain and the mountain drag are both predicted to be

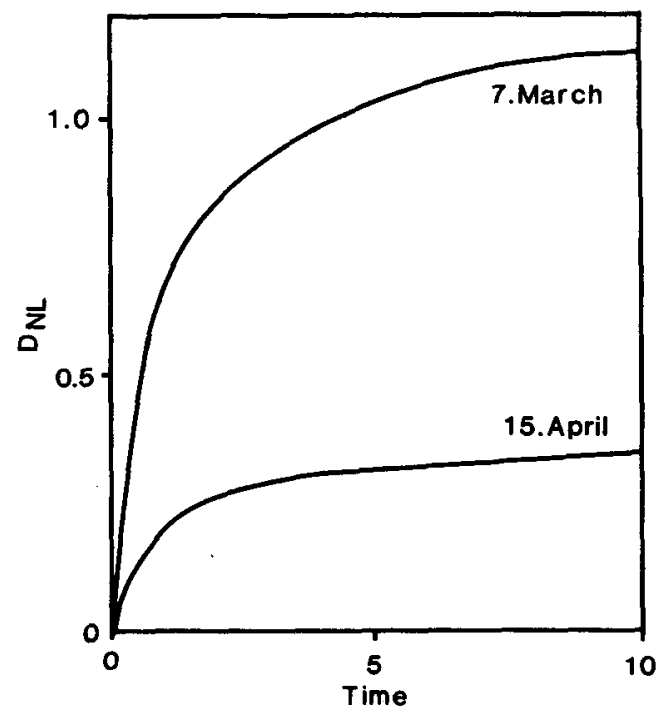

Fig. 20. Evolution in time of the mountain drag for two bora cases. The mountain drag is given in $\mathrm{Pa}$ and the time in $\mathrm{h}$. greater in the cyclonic type of bora than in the anticyclonic case, which corroborates the observations.

Acknowledgments. I would like to express my gratitude to Roger Pielke for providing a tape with the coding of the UVM model. Thomas Jank is thanked for providing Long's solution.

\section{REFERENCES}

Clark, T. L., and R. D. Farley, 1984: Severe downslope windstorm calculations in two and three spatial dimensions using anelastic interactive grid nesting: A possible mechanism for gustiness. Mon. Wea. Rev., 41, 329-350.

Durran, D. R., and J. B. Klemp, 1983: A compressible model for the simulation of most mountain waves. Mon. Wea. Rev., 111, 2341-2361.

Klemp, J. B., and D. K. Lilly, 1975: The dynamics of waveinduced downslope winds. J. Atmos. Sci. 32, 320-339.

- and - 1978: Numerical simulation of hydrostatic mountain waves. J. Atmos. Sci., 35, 78-107.

Lilly, D. K., 1969: The numerical simulation of three-dimensional turbulence with two dimensions. Proc. Int. Symp. High Speed Computing in Fluid Dynamics, Monterey, F. N. Frenkiel and K. Stewartson, Eds. Amer. Inst. Phys.

mountain wave and its associated momentum flux and energy dissipation. J. Atmos. Sci., 30, 1135-1152.

—_, and J. B. Klemp, 1979: The effects of the terrain shape on nonlinear hydrostatic mountain waves. J. Fluid Mech., 95, 241-261.

Long, R. R., 1953: Some aspects of the flow of stratified fluids. A theoretical investigation. Tellus, 5, 42-58.

$\longrightarrow$ 1954: Some aspects of the flow of stratified fluids. Experiments with a two-fluid system. Tellus, 6, 97-115.

Mahrer, Y., and R. A. Pielke, 1977: A numerical study of the airflow over irregular terrain. Contrib. Atmos. Phys., 50, 98113.

techniques for the advective terms in a numerical mesoscale model. Mon. Wea. Rev., 106, 818-830.

Miles, J. W., and H. E. Huppert, 1969: Lee waves in a stratified flow. Part 4. Perturbation approximations. J. Fluid Mech., 35, 497.

Orlanski, I., 1976: A simple boundary condition for unbounded hyperbolic flows. J. Comput. Phys., 21, 251-269.

Peltier, W. R., and T. L. Clark, 1979: The evolution and stability of finite-amplitude mountain waves. Part II: Surface wave drag and severe downslope windstorms. J. Atmos. Sci., 36, 14991529.

Pielke, R. A., 1974: A comparison of three-dimensional and twodimensional predictions of sea breezes. J. Atmos. Sci., 31, $1577-1585$.

- , and Y. Mahrer, 1975: A numerical study of the airflow over mountains using the two-dimensional version of the University of Virginia mesoscale model. J. Atmos. Sci., 32, 2144-2155.

- and - , 1978: Verification analysis of the University of Virginia three-dimensional mesoscale model prediction over South Florida for 1 July 1973. Mon. Wea. Rev., 106, 15681589.

Queney, P., 1948: The problem of airflow over mountains. A summary of theoretical studies. Bull. Amer. Meteor. Soc., 29, 16-26.

Smith, R. B., 1977: The steepening of hydrostatic mountain waves. J. Atmos. Sci., 34, 1634-1654.

- 1981: The influence of mountains on the atmosphere Advances in Geophysics, Vol. 21, Academic Press, 87-228.

- 1982: Aerial observations of the Yugoslavian bora: Preliminary results. GARP-ALPEX No. 7, 187-201. [Available from WMO, Case postale No. 5, CH-1211, Geneva 20, Switzerland.]

Yoshino, M. M., 1976: Local Wind Bora. University of Tokyo Press, 289 pp. 